\title{
Evaluation of cytoplasmic genetic effects for production and reproduction traits in Afrikaner cattle
}

\author{
F.W.C. Neser ${ }^{1 \#}$, J.B. van Wyk ${ }^{1}$ \& M.M. Scholtz ${ }^{1,2}$ \\ ${ }^{1}$ Department of Animal, Wildlife and Grassland Sciences, University of the Free State, P.O. Box 339, \\ Bloemfontein, 9300, South Africa \\ ${ }^{2}$ ARC-Animal Production Institute, Private Bag X2, Irene, 0062, South Africa
}

(Received 4 January 2014; Accepted 5 June 2014; First published online 3 December 2014)

Copyright resides with the authors in terms of the Creative Commons Attribution 2.5 South African Licence.
See: http://creativecommons.org/licenses/by/2.5/za
Condition of use: The user may copy, distribute, transmit and adapt the work, but must recognise the authors and the South African
Journal of Animal Science.

\begin{abstract}
The influence of cytoplasmic effects on weaning weight (WW) and age at first calving (AFC) were investigated in the South African Afrikaner beef breed. A total of 14535 AFC records (1974 - 2008) and 68 152 WW records (1974 - 2011) were used in the estimation of variance components. All cows were assigned to different damlines, using the pedigree information available. The model used for WW include direct additive, maternal additive, the covariance between the animal-, permanent maternal environmental-, herdyear-season $x$ sire- and damline effects, while the simplest model which include only direct- and damline effects were used for AFC. The contribution of the cytoplasmic effects to the total variance was negligible (less than $0.5 \%$ ) for both traits. These results suggest that cytoplasmic effects can be ignored in genetic evaluations of Afrikaner cattle for the traits investigated.
\end{abstract}

Keywords: Age at first calving, beef cattle, damline, weaning weight

\#Corresponding author: neserfw@ufs.ac.za

\section{Introduction}

The Afrikaner beef cattle breed is an important component of the South African beef industry, being promoted as a dam line for crossbreeding purposes. For cow families to be more important than indicated by estimates of additive genetic effects, functional genetic material in the cytoplasm of oocytes must be present (Tess \& MacNeil, 1994). Cytoplasmic genetic effects are transmitted directly only from mother to offspring through mitochondrial DNA.

Normal genetic evaluation programmes focus mainly on the genes in the nucleus of an animal's cells. The mitochondrial genes that are involved in the regulation of cellular energy metabolism could also be targeted in a selection programme. The question is do these genes have a significant influence on the genetic parameters that are normally estimated in genetic improvement programmes and therefore rendering them inaccurate. Previous investigations have failed to detect important cytoplasmic effects on performance traits in beef cattle (Tess \& Robison, 1990; Northcutt et al., 1991; Tess \& MacNeil, 1994).

The focus of this study was to investigate the influence of cytoplasmic effects on genetic parameters of weaning weight (WW) and age at first calving (AFC) in the South African Afrikaner beef cattle breed using mixed model methodology.

\section{Materials and Methods}

A total of 14535 age at first calf records (1974 - 2008) and 68152 weaning weight records (1974 2011) of the Afrikaner cattle breed participating in the national recording scheme were used in the analysis. Cytoplasmic lines were identified from extensive pedigrees and constituted animals that shared a common cytoplasmic source. All cows in the dataset were thus assigned to different damlines, using all pedigree information available. A total of 4495 damlines was assigned for WW while 3975 were assigned for AFC. At least five cows per damline for WW and two cows per damline for AFC were used in the estimation of variance components using ASREML (Gilmour et al., 2009). A summary of the performance and pedigree data used in the analysis are presented in Tables 1 and 2, respectively.

To assess the influence of non-genetic factors on the different weights for inclusion in the model, an analysis of variance was done using SAS's Proc GLM program (2009). A stringent significant level of $P$ 
$<0.01$ was used as criteria for inclusion. Fixed effects fitted were sex (male, female) and a concatenation of breeder, year and season. Age of dam was fitted as a linear regression. All weaning weights were preadjusted to 205 days to simplify the analysis. Herds with less than three years of recording as well as contemporary groups with less than five records were also removed from the final data used for the analysis. All contemporary groups had at least two sires present.

Table 1 Descriptive statistics for age at first calving (AFC) (months) and weaning weight (WW) (kg)

\begin{tabular}{crrrrr}
\hline \multicolumn{1}{c}{$\mathbf{n}$} & Mean & SD & Min & Max \\
\hline AFC & 14535 & 36.5 & 4.75 & 21 & 49 \\
WW & 68152 & 185.4 & 30.11 & 70 & 304 \\
\cline { 4 - 6 }$=$ number of observations; SD = standard deviation; Min = minimum; Max = maximum.
\end{tabular}

Table 2 Descriptive statistics of pedigree data for age at first calving (AFC) (months) and weaning weight $(\mathrm{WW})(\mathrm{kg})$

\begin{tabular}{cccccccc}
\hline & Sires & SS & DS & Dams & SD & DD & Gen \\
\hline AFC & 1820 & & & 8215 & 1125 & 3439 & 8 \\
WW & 2266 & 517 & 1029 & 22968 & 1481 & 7860 & 9
\end{tabular}

SS = Sires of sires; DS = Dams of sires; SD = Sires of dams;

$\mathrm{DD}=$ dams of dams; Gen = number of generations.

Taking into consideration both the distribution of records over a 12 month period as well as the weaning weights of the calves, two distinct seasons were identified. The months from September to March were classified as season one, while April to August were classified as season two. Age of dam was express in years starting with dams of two years and younger. All dams older than six years were grouped together.

Eight different models were fitted for WW while only three were tested for AFC. (Co)variance components as well as heritabilities were estimated using the ASREML program (Gilmour et al., 2009). The Log likelihood ratio test was used to obtain the most suitable model for the analysis. A random effect was considered significant when its inclusion in the model caused a significant improvement in the log likelihood ratio. A chi-square distribution of $\alpha=0.05$ at one degree of freedom was used as a test statistic (3.841). When -2 times the difference between the log likelihoods was greater than this critical value, the inclusion of the particular random effect was considered to significantly improve the fit of the model (Swalve, 1993). Only the models used for both AFC and WW are presented.

Model used for age at first calving:

Where: -

$$
Y=X \beta+Z_{1} a+Z_{2} c+\varepsilon
$$

$Y=$ vector of observations,

$\beta=$ vector of fixed effects influencing age at first calving,

$\mathrm{a}=$ vector of direct additive effects,

$\mathrm{c}=$ vector of additional random damline effects,

$\varepsilon=$ vector of residuals and

$\mathrm{X}, \mathrm{Z}_{1}$ and $\mathrm{Z}_{2}$ were incidence matrices relating observations to their respective fixed and random effects.

Model used for weaning weight:

Where: -

$$
\begin{aligned}
& Y=X \beta+Z_{1} a+Z_{2} m+Z_{3} c_{1}+Z_{4} c_{2}+Z_{5} c_{3}+\varepsilon \\
& \{\text { with cov }(a, m)=A \sigma a m\}
\end{aligned}
$$

$Y=$ vector of weaning weight observations,

$\beta=$ vector of fixed effects influencing weaning weight, 
$\mathrm{a}=$ vector of direct additive effects,

$\mathrm{m}=$ vector of random maternal additive (dam) effects,

$\mathrm{C}_{1}=$ vector of additional random damline effects,

$\mathrm{c}_{2}=$ vector of random permanent maternal environmental effects,

$\mathrm{C}_{2}=$ vector of additional random effects of herd-year-season $\mathrm{x}$ sire interaction,

$\varepsilon=$ vector of residuals and

$X, Z_{1}, Z_{2}, Z_{3}, Z_{4}$ and $Z_{5}$ were incidence matrices relating observations to their respective fixed and random effects.

\section{Results and Discussion}

The most comprehensive model, which included direct additive, maternal additive, direct-maternal covariance, permanent maternal environmental-, herd year season $\mathrm{x}$ sire- and damline effects, was the most appropriate model for WW, while the simplest model which include only direct- and damline effects were used for AFC. All fixed effects tested had a significant effect on the traits analyzed and were thus retained in the different models. The (co)variance and ratio estimates using the most appropriate model for WW and AFC are presented in Table 3.

Table 3 (Co)variance and ratio estimates using the most appropriate model for weaning weight (WW) and age at first calving (AFC)

\begin{tabular}{lcc}
\hline & WW & AFC \\
\hline (Co)variance & & \\
Direct additive variance & 70.55 & 1.920 \\
Maternal additive variance & 51.57 & - \\
Variance due to damline & 1.47 & 0.006 \\
Direct - maternal covariance & -23.99 & - \\
Permanent maternal environmental variance & 56.24 & - \\
Herd year season x sire variance & 58.11 & - \\
Error variance & 296.58 & 13.978 \\
Phenotypic variance & 510.56 & 15.905 \\
(Co)variance ratios & & \\
Direct heritability & $0.14(0.015)$ & $0.12(0.028)$ \\
Maternal heritability & $0.10(0.011)$ & \\
Damline & $0.003(0.003)$ & $0.0004(0.014)$ \\
Permanent maternal environment & $0.11(0.007)$ & \\
Herd year season $x$ sire interaction & $0.11(0.005)$ & \\
Correlation between animal effects & $-0.40(0.058)$ & \\
& & \\
\hline
\end{tabular}

The direct and maternal heritability for WW was in correspondence with that obtained by various authors ranging between 0.07 - 0.57 for direct ((Schoeman \& Jordaan, 1999; Plasse et al., 2002) and 0.06 0.21 for maternal (Haile-Mariam \& Kessa-Mersa, 1995; Diop \& Van Vleck, 1998). The estimate for herd year season $x$ sire interaction for WW (0.11) is higher than results obtained by Neser et al. (1996) (0.08) in Bonsmara cattle as well as Pico et al. (2004) (0.06) in Brahman cattle but in line with results obtained by Neser et al. (2012) (0.10) in Brangus cattle. This high estimate indicates that some re-ranking of sires might occur over different contemporary groups.

The heritability estimate for age at first calving is much lower (0.12) than the estimates obtained by Bormann \& Wilson (2010) in Angus cattle that varied from $0.27-0.35$ as well as the 0.22 obtained by Frazier et al. (1999) and 0.24 obtained by Toelle \& Robison (1985). It is, however, higher than the reported mean heritability of Koots et al. (1994) (0.06).

The ratio of the cytoplasmic effect as proportion of the phenotypic variance was 0.003 and 0.0004 for WW and AFC respectively which can be considered as negligible. These results were similar to those found by Tess \& MacNeil (1994) who concluded that for growth traits up to a year, selection should be based on 
estimates of additive genetic merit without additional emphasis on maternal lineage. Similar results were also obtained by Pritchard et al. (2007) in Welsh Mountain sheep for different weight traits. Pun et al. (2012) concluded that cytoplasmic lines may have a marginal effect on growth performance in beef cattle but not sufficient in magnitude to justify their inclusion in models in beef improvement schemes after analysing birth weight and preweaning growth traits in the Asturiana de los Valles beef cattle breed.

\section{Conclusions}

The contribution of the cytoplasmic effects to the total variance was negligible (less than $0.5 \%$ ) for both traits. These results suggest that cytoplasmic effects can be ignored in genetic evaluations of Afrikaner beef cattle for the traits investigated.

\section{References}

Bormann, J.M. \& Wilson, D.E., 2010. Calving day and age at first calving in Angus heifers. J. Anim. Sci. 88, 1947-1956.

Diop, M. \& Van Vleck, L.D., 1998. Estimates of genetic parameters for growth traits of Gobra cattle. Anim. Sci. 66, 349-355.

Frazier, E.L., Sprott, L.R., Sanders, J.O., Dahm, P.F., Crouch, J.R. \& Turner, J.W., 1999. Sire marbling score expected progeny difference and weaning weight maternal expected progeny difference associations with age at first calving and calving interval in Angus beef cattle. J. Anim. Sci. 77, 1322-1328.

Gilmour, A.R., Gogel, B.J., Cullis, B.R. \& Thompson, R., 2009. ASReml User Guide Release 3.0 VSN International Ltd, Hemel Hempstead, HP1 1ES, UK www.vsni.co.uk.

Haile-Mariam, M. \& Kassa-Mersa, H., 1995. Estimates of direct and maternal covariance components of growth traits in Boran cattle. J. Anim. Breed. 113, 43-55.

Koots, K.R., Gibson, J.P. \& Wilton, J.W., 1994. Analyses of published genetic parameters estimates for beef production traits. 1. Heritability. Anim. Breed. Abst. 62, 309.

Neser, F.W.C., Konstantinov, K.V. \& Erasmus, G.J., 1996. The inclusion of herd-year-season by sire interaction in the estimation of genetic parameters in Bonsmara cattle. S. Afr. J. Anim. Sci. 26, 75-78.

Neser, F.W.C., Van Wyk, J.B., Fair, M.D., Lubout, P. \& Crook, B., 2012. Estimation of genetic parameters for growth traits in Brangus cattle. S. Afr. J. Anim. Sci. 42 (Suppl. 1), 469-473.

Northcutt, S.L., Willham, R.L. \& Wilson, D.E., 1991. Genetic parameters for nuclear and non-nuclear inheritance in three synthetic lines of beef cattle differing in mature size. J. Anim. Sci. 69, 745.

Pico, B.A., Neser, F.W.C. \& Van Wyk, J.B., 2004. Genetic parameters for growth traits in South African Brahman cattle. S. Afr. J. Anim. Sci. 34 (Suppl. 2), 44-46.

Plasse, D., Verde, O., Fossi, H., Romero, R., Hoogesteijn, R., Bastidas, P. \& Bastardo, J., 2002. (Co)variance components, genetic parameters and annual trends for calf weights in a pedigree Braham herd under selection for three decades. J. Anim. Breed. Genet. 119, 141-153.

Pritchard, T., Cahalan, C. \& Dewi, I.A.P., 2008. Exploration of cytoplasmic inheritance as a contributor to maternal effects in Welsh Mountain sheep. Genet. Sel. Evol. 40, 309-319.

Pun, A., Goyache, F., Cervantes, I. \& Gutiérrez, J.P., 2012. Cytoplasmic line effects for birth weight and preweaning growth traits in the Asturiana de los Valles beef cattle breed. Livest. Sci. 143, 177-183.

SAS, 2010. Statistical Analysis System. Cary, North Carolina USA.

Swalve, H.H., 1993. Estimation of direct and maternal (co)variance components for growth traits in Australian Simmental beef cattle. J. Anim. Breed. Genet. 110, 241-252.

Schoeman, S.J. \& Jordaan, G.F., 1999. Multitrait estimation of direct and maternal (co)variances for growth and efficiency traits in a multibreed beef cattle herd. S. Afr. J. Anim. Sci. 29, 124-136.

Tess, M.W. \& MacNeil, M.D., 1994. Evaluation of cytoplasmic genetic effects in Miles City Line 1 Hereford cattle. J. Anim. Sci. 72, 851-856.

Tess, M.W. \& Robison, O.W., 1990. Evaluation of cytoplasmic genetic effects in beef cattle using an animal model. J. Anim. Sci. 68, 1899-1909.

Toelle, V.D. \& Robison, O.W., 1985. Estimates of genetic correlations between testicular measurements and female reproductive traits in cattle. J. Anim. Sci. 60, 89-100. 